Worker Safety and Health and Nuclear Safety Quarterly Performance Analysis (January - March 2008)

C. E. Kerr

October 8, 2009 
This document was prepared as an account of work sponsored by an agency of the United States government. Neither the United States government nor Lawrence Livermore National Security, LLC, nor any of their employees makes any warranty, expressed or implied, or assumes any legal liability or responsibility for the accuracy, completeness, or usefulness of any information, apparatus, product, or process disclosed, or represents that its use would not infringe privately owned rights. Reference herein to any specific commercial product, process, or service by trade name, trademark, manufacturer, or otherwise does not necessarily constitute or imply its endorsement, recommendation, or favoring by the United States government or Lawrence Livermore National Security, LLC. The views and opinions of authors expressed herein do not necessarily state or reflect those of the United States government or Lawrence Livermore National Security, LLC, and shall not be used for advertising or product endorsement purposes.

This work performed under the auspices of the U.S. Department of Energy by Lawrence Livermore National Laboratory under Contract DE-AC52-07NA27344. 


\section{Worker Safety and Health and Nuclear Safety Quarterly Performance Analysis (January - March 2008)}

March 2009

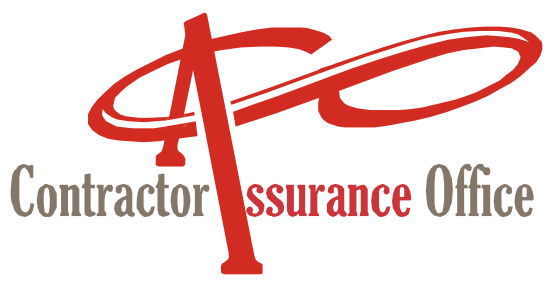




\section{Contents}

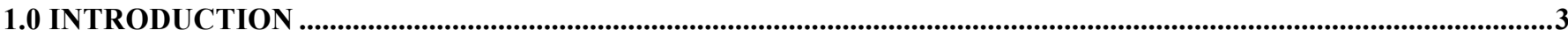

2.0 INTERNAL ASSESSMENTS THAT EVALUATE WSH AND NUCLEAR SAFETY ..........................................4

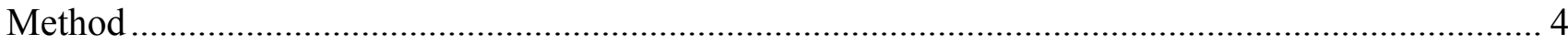

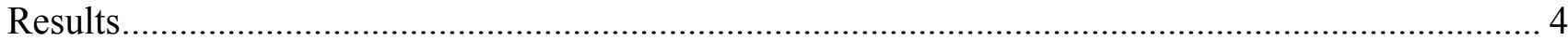

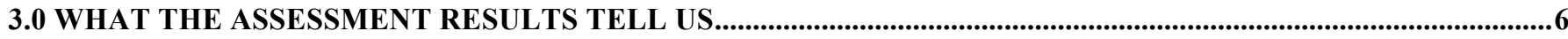

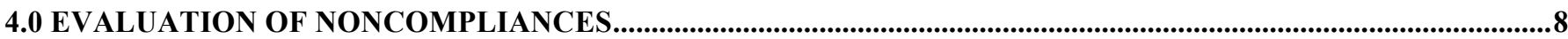

4.1 NONCOMPLIANCES RELATED TO EVENTS OR CONDITIONS ......................................................................8

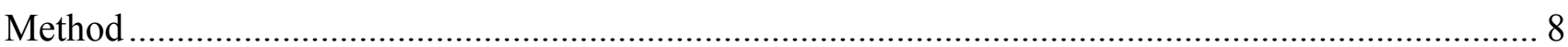

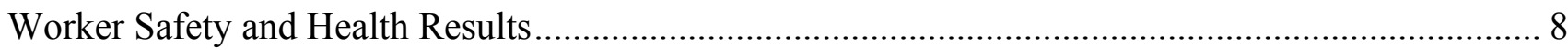

Nuclear Safety Results....................................................................................... 9

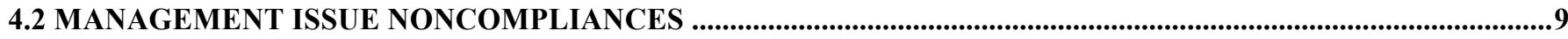

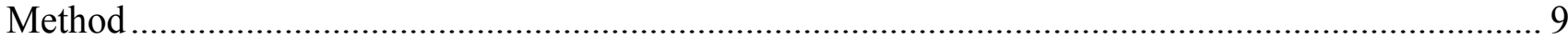

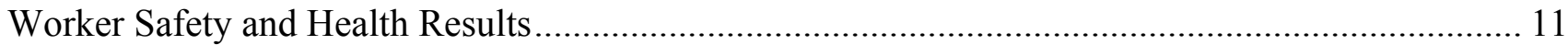

Nuclear Safety Results .......................................................................................... 19

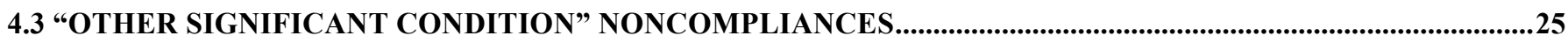

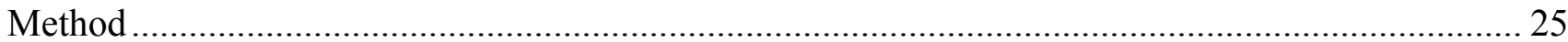

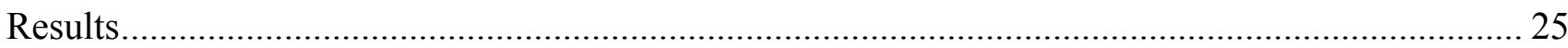

5.0 HOW IS LLNL RESPONDING TO AND/OR MANAGING WHAT WE ARE FINDING? ......................................26

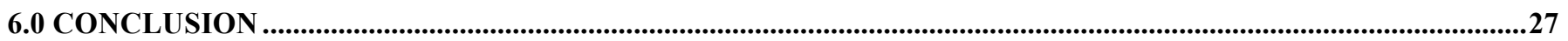




\subsection{Introduction}

The DOE Office of Enforcement expects LLNL to "implement comprehensive management and independent assessments that are effective in identifying deficiencies and broader problems in safety and security programs, as well as opportunities for continuous improvement within the organization" and to "regularly perform assessments to evaluate implementation of the contractor's processes for screening and internal reporting." LLNL has a self-assessment program, described in ES\&H Manual Document 4.1, that includes line, management and independent assessments. LLNL also has in place a process to identify and report deficiencies of nuclear, worker safety and health and security requirements.

In addition, the DOE Office of Enforcement expects LLNL to evaluate "issues management databases to identify adverse trends, dominant problem areas, and potential repetitive events or conditions" (page 14, DOE Enforcement Process Overview, December 2007). LLNL requires that all worker safety and health and nuclear safety noncompliances be tracked as "deficiencies" in the LLNL Issues Tracking System (ITS). Data from the ITS are analyzed for worker safety and health (WSH) and nuclear safety noncompliances that may meet the threshold for reporting to the DOE Noncompliance Tracking System (NTS).

This report meets the expectations defined by the DOE Office of Enforcement to review the assessments conducted by LLNL, analyze the issues and noncompliances found in these assessments, and evaluate the data in the ITS database to identify adverse trends, dominant problem areas, and potential repetitive events or conditions. The report attempts to answer three questions:

Is LLNL evaluating its programs and state of compliance?

What is LLNL finding?

Is LLNL appropriately managing what it finds?

The analysis in this report focuses on data from the first quarter of 2008 (January through March). This quarter is analyzed within the context of information identified in previous quarters to include April 2007 through March 2008.

The results from analyzing the deficiencies are presented in accordance with the two primary NTS reporting thresholds for WSH and nuclear safety noncompliances: 1) those related to certain events or conditions and 2) those that are management issues. In addition, WSH noncompliances were also analyzed to determine if any fell under the "other significant condition" threshold. This report also identifies noncompliance topical areas that may have issues that do not meet the NTS reporting threshold but should remain under observation. These are placed on the "watch list" for continued analysis. 


\subsection{Internal assessments that evaluate WSH and nuclear safety}

\section{Method}

Internal assessments at LLNL include internal independent assessments chartered by the Director's Office, management self-assessments chartered by functional area managers, and line self-assessments chartered by the principal associate director or the associate director. DOE and regulatory agencies conduct external assessments. The results of all these types of assessments are entered in the ITS. Deficiencies, issues and corrective actions identified by events such as illnesses/injuries and occurrences are also entered into ITS.

Data on assessments were pulled from ITS in mid-April and reviewed to determine if the frequency or types of assessments changed during this period. The ITS allows for assessments to be designated by type of assessments and organization performing the assessment. For this analysis, the selections were binned into four assessing methods. The assessing method variable was derived from combinations of the "assessment type" and "assessment performed by" fields. The assessing methods were categorized into the following four categories:

- "Self" consisted of assessments designated as walkthroughs, required self-assessments, and inspections and as conducted by either the subject matter expert or the directorate.

- "Independent" consisted of assessments designated as independent assessments and as conducted by ES\&H Assurance Office, Audit and Oversight and other Director's Office or Deputy Director for Operations.

- "External" consisted of assessments designated as external assessments and as conducted by LLNL with Livermore Site Office, National Nuclear Security Administration local site office, other external, Department of Energy and other DOE/NNSA offices, regulatory agencies and assessment type inspections, conducted by regulatory agencies.

- "Event" consisted of assessment types: occurrence, Case Analysis Report, and incident analysis.

- "Other" consisted of all other combinations of assessment types and assessment performed by that could not be grouped into the specified categories above.

\section{Results}

During the 12-month period of April 2007 - March 2008, LLNL entered 265 management selfassessments, 1 independent assessment, and 21 events. During this same 12-month period, 22 external assessments were entered. An additional 320 assessments were entered that could not be attributed to any of the above categories, predominantly because the associated assessment information was inconsistent or contradictory (For example, a self-assessment conducted by DOE). These assessments were grouped into an "other" category and are included, however, in the analysis below. The number of internal assessments in the January through March 2008 quarter was 109, a significant decrease since 2007 when the average number of internal assessments per quarter was 185 . Figure 1 displays the number of assessments by quarter and type from January 2005 to March 2008. 
Figure 1. The number of Assessments by Type and Quarter

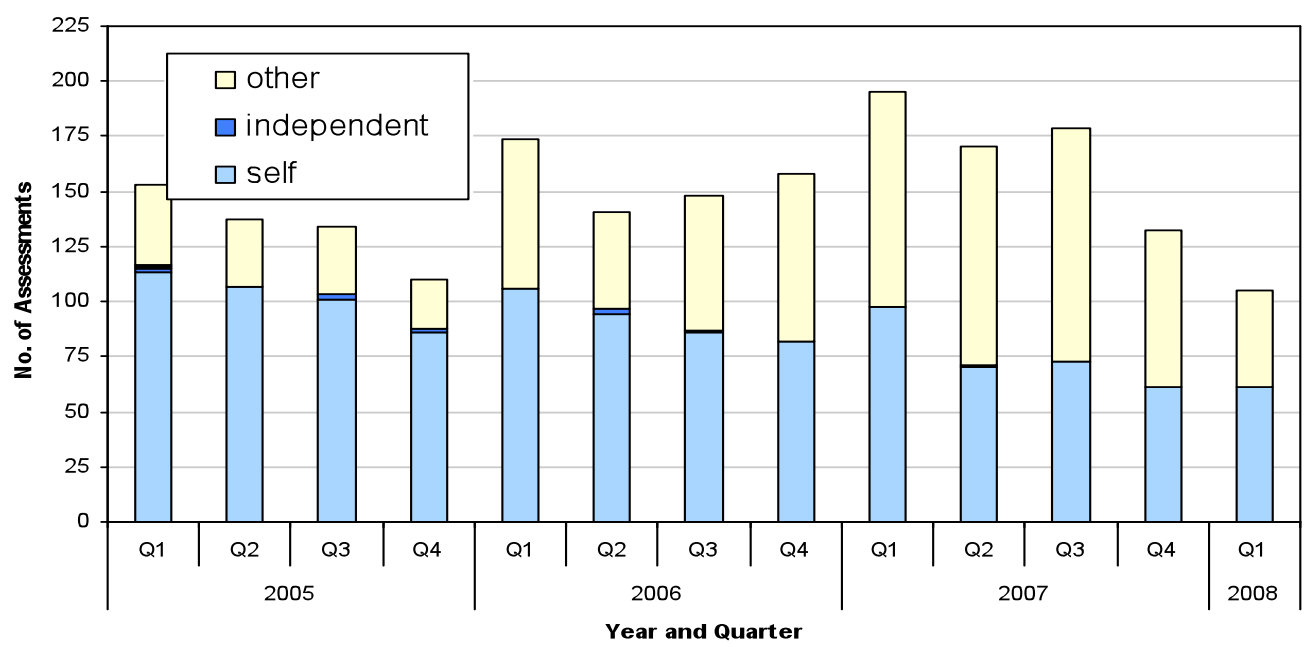

There has been a decreasing trend in the number of internal assessments entered into ITS since the third quarter of 2007. In fact, during the January -March 2008 quarter, LLNL entered the fewest number of internal assessments in three years. A control chart was created to determine the level of concern. When evaluating the number of assessments conducted each quarter using a process control chart (Figure 2), none of the data points are above or below the control limits, meaning the process remains in a state of control.

In reviewing Figure 2, if the fourth quarter of 2007 and the first quarter of 2008 were excluded from the chart, observationally there appears to be an increasing trend since 2005. After testing this with a simple linear regression, the increasing trend was statistically significant ( $p$-value $<0.05$ ), and is shown on Figure 2 as a trend line up to the third quarter in 2007. After including the fourth quarter of 2007 and the first quarter of 2008, the increasing trend may still be present but is no longer statistically significant ( $p$-value $=0.76$ ). This supports the observation that the number of assessments entered into ITS has recently declined since the third quarter in 2007. One possible explanation for the decrease in assessments during this period is the impact of contract transition.

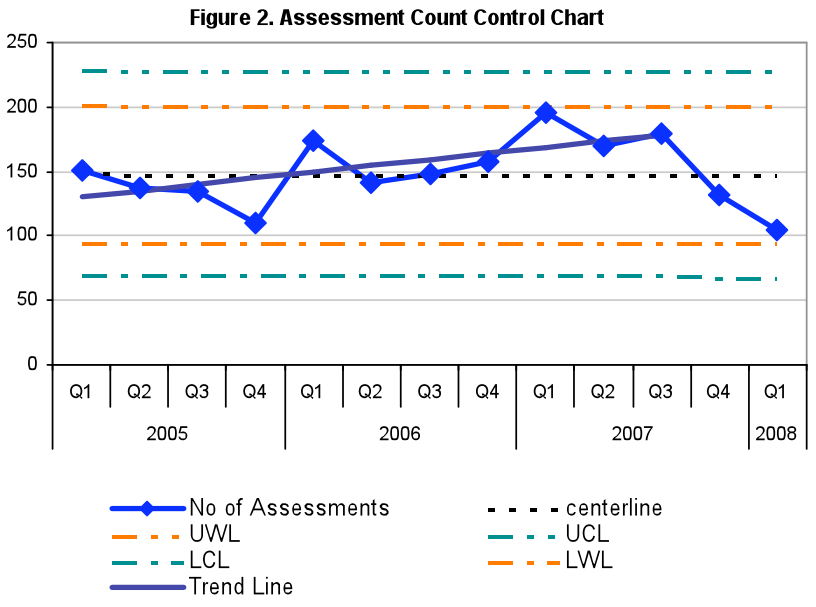




\subsection{What the assessment results tell us}

In the January through March 2008 quarter, 773 deficiencies from all sources were entered in ITS. Of these, 561 (73\%) were marked as WSH site-reportable noncompliances and $30(4 \%)$ were marked as nuclear safety site-reportable noncompliances. Six $(0.8 \%)$ of the noncompliances were reported to the DOE NTS. This ratio is fairly consistent with the average for the previous three quarters when, on average, $76 \%$ of the deficiencies were marked WSH site-reportable noncompliances, 5\% were marked as nuclear safety site-reportable noncompliances and $1 \%$ were reported to the DOE NTS.

The reasons for the reduced number of deficiencies identified and entered in ITS in this quarter (when compared to previous quarters) can be improved compliance, a reduction in the number of assessments, reduction in the scope of assessments, or other changes.

Table 1. ITS Deficiencies Screened, Site-reported and NTS reported Noncompliances

\begin{tabular}{|c|c|c|c|c|c|c|}
\hline Year & Quarter & $\begin{array}{l}\text { ITS Deficiencies } \\
\text { Entered in ITS }\end{array}$ & $\begin{array}{c}\text { WSH Site } \\
\text { Reported NCs } \\
\text { (\% of defs entered) }\end{array}$ & $\begin{array}{c}\text { WSH NCs } \\
\text { Reported to NTS } \\
\text { (\% of site reported } \\
\text { NCs) }\end{array}$ & $\begin{array}{c}\text { Nuclear Safety } \\
\text { Site Reported } \\
\text { NCs } \\
\text { (\% of defs entered) }\end{array}$ & $\begin{array}{c}\text { Nuclear Safety } \\
\text { NCs Reported to } \\
\text { NTS } \\
\text { (\% of site reported } \\
\text { NCs) }\end{array}$ \\
\hline \multirow{3}{*}{2007} & Q2 & 875 & $588(67 \%)$ & $9(2 \%)$ & $18(2 \%)$ & $2(11 \%)$ \\
\hline & Q3 & 1626 & $1310(81 \%)$ & $7(<1 \%)$ & $87(5 \%)$ & $7(8 \%)$ \\
\hline & Q4 & 1068 & $800(75 \%)$ & $7(<1 \%)$ & $58(5 \%)$ & $4(7 \%)$ \\
\hline 2008 & Q1 & 773 & $561(73 \%)$ & $3(<1 \%)$ & $30(4 \%)$ & $3(10 \%)$ \\
\hline
\end{tabular}

In this case, the variation can be attributed to special focused assessments that when performed caused an increase in deficiencies in two previous quarters. There were significantly more deficiencies entered into ITS in the third quarter of 2007 compared to the other three quarters shown in Table 1. During this quarter 444 of the 1626 deficiencies (27\%) were from the WSHA ladder assessment and $338(21 \%)$ were the category A and B deficiencies found during the LLNS due diligence walkdowns (Table 2). In the fourth quarter of 2007, 145 of the 1068 (14\%) were additional category B deficiencies found during the LLNS due diligence walkdowns (Table 2). Without these special assessments, the number of deficiencies would have been 844 in the third quarter of 2007 and 923 in the fourth quarter of 2008. In comparing the number of deficiencies in the first quarter of 2008 to the number of deficiencies in the other two quarters without these special assessments, they appear to be similar. 
Table 2. LLNS Due Diligence Deficiencies and Entry into ITS

\begin{tabular}{|l|c|c|c|c|c|}
\hline & Total & $\begin{array}{c}\text { Entered as } \\
\text { Issues in ITS }\end{array}$ & \multicolumn{3}{|c|}{ Entered as Deficiencies in ITS } \\
\hline & & & Q3 2007 & Q4 2007 & Total \\
\hline A & 35 & 6 & 29 & 0 & 29 \\
\hline B & 2328 & 548 & 309 & 145 & 454 \\
\hline \hline Total & 2363 & 554 & 338 & 145 & 483 \\
\hline
\end{tabular}

Although the deficiencies found during the LLNS due diligence walkdowns influenced the quarterly numbers of deficiencies entered into ITS (Table 1), there should have been more of a discrepancy between the third and fourth quarters of 2007 compared to all other quarters listed in Table 1. Based on Table 2, only 20\% (483) of category B deficiencies found during the LLNS due diligence walkdowns were entered into ITS as deficiencies. Some category B deficiencies found during the LLNS walkdowns were put into ITS as issues $(24 \%)$ and therefore were not included in this analysis. 


\subsection{Evaluation of Noncompliances}

This section evaluates the identified noncompliances for specific topical areas that may need attention. LLNL requires that all worker safety and health and nuclear safety noncompliances be tracked as "deficiencies" in the Issues Tracking System (ITS). Each deficiency entered into ITS is assigned a compliance code. There are four levels to a compliance code: class, heading, title and number. For example, in compliance code S-IS-EL.01, S (Safety) is the class, IS (Industrial Safety) is the heading, EL (Electrical) is the title and .01 is the number.

\subsection{Noncompliances Related to Events or Conditions}

DOE expects that noncompliances associated with certain Occurrence Reporting and Processing System (ORPS) reporting criteria be reported to the NTS, regardless of the severity of the noncompliance. LLNL uses the NTS reporting thresholds specified in the DOE Enforcement Process Overview, Appendices A and B and described in ESEH Manual, Document 4.4, Identifying, Reporting, and Tracking Noncompliances with Nuclear Safety and Worker Safety and Health Requirements.

\section{Method}

Occurrences are reviewed promptly for NTS-reportable WSH and nuclear safety noncompliances, as they are reported into the ORPS. The initial review is based on the description of the occurrence. However, after the occurrence is further characterized and analyzed for causes, additional information may be available that identifies noncompliances that should be reported. The Contractor Assurance Office works with the directorate point of contact to make this determination.

\section{Worker Safety and Health Results}

There were ten occurrence reports submitted in the first quarter of 2008. Of these ten occurrence reports, three met a NTS reporting threshold for WSH:

(1) “Electrical Shock at Building 151 during Main Electrical Service Equipment Replacement Project" (LLNL-2008-0004)

(2) "Bike Accident Results in Fracture" (LLNL-2008-0007)

(3) "Failure to Follow Established Work Procedures Results in Potentially Hazardous Building 241 Air Leak" (LLNL-2008-0010).

Each of these occurrences was evaluated for possible noncompliances. Two of these occurrence reports were identified to have a WSH noncompliance(s) associated with the event and were reported into the NTS: the electrical shock (LLNL-2008-0004) and the potentially hazardous air leak (LLNL-2008-0010). The path and bike accident scene for the second occurrence, above (LLNL-2008-0007) was reviewed by an industrial safety engineer and injury case investigator 
and no deficient conditions were identified. Therefore, a noncompliance was not associated with the event and a noncompliance report was not entered into the NTS.

\section{Nuclear Safety Results}

Of the ten occurrence reports submitted in the first quarter of 2008, only one met a NTS reporting threshold as a nuclear safety noncompliance:

"Degradation of the Building 332 Fire Detection and Alarm System" (LLNL-2008-0002).

During the semi-annual MXL Fire Detection and Alarm System Battery Load surveillance test and contrary to surveillance requirements, when $\mathrm{AC}$ power was disconnected during the test the backup battery system did not sense the loss of normal power. A critique was held in accordance with facility protocol and the deficient condition was corrected by a like-in-kind replacement of the failed battery.

\subsection{Management Issue Noncompliances}

Management issue noncompliances are defined as repetitive noncompliances, programmatic issues and intentional violations or misrepresentations. One goal of this analysis is to identify a programmatic issue through a review of multiple deficiencies within the same compliance code title (the third level of the compliance code). Secondarily, the analysis may identify a previously overlooked repetition of the same type of deficiency. A programmatic problem generally involves some weakness in administrative or management controls or their implementation, to such a degree that a broader management or process control problem exists. A repetitive problem is generally two or more different events that involve substantially similar conditions, locations, equipment, or individuals. Repetitive problems tend to be narrower in scope than programmatic problems.

\section{Method}

Analysis included a three-step process of first looking at the data as a whole to identify visual variations; second, performing statistical tests of the sets of data gleaned from the first step, and third, evaluating this remaining set of data by reviewing the context of the noncompliances, such as, discovery method, location in terms of facility, and the last level of the compliance code, the description of the noncompliance.

Data was extracted from ITS in mid-April using the ITS Basic Deficiency Report. This data comprised 14,881 deficiencies identified under the compliance code classes "safety and health," 


\section{Worker Safety and Health and Nuclear Safety - Quarterly Analysis}

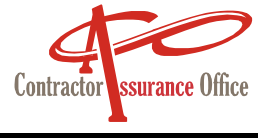

"management," "environment" and "safety basis," with notification dates in 2005, 2006, 2007 and through March 2008.

Of the 14,881 deficiencies 11,060 were identified by the 48 compliance code titles under the class "safety and health" in 2005-March 2008, and were used in the safety title control chart analysis discussed in this report. Of these deficiencies, 523 had notification dates from January 2008 to March 2008.

The process for analyzing this data was to review the deficiencies by quarter, over the last three years and the quarter in question (2005-March 2008), looking for groupings with large numbers of deficiencies, observed changes in the number of deficiencies, or other observations that look different from what is expected. Then, if the numbers appeared to be of interest, two control charts were created for compliance code titles within the "safety and health" class.

A control chart can be considered a way of performing a statistical test, a test whether the process is in a state of control. Two control charts were used to look at variation for the compliance code titles within the "safety and health" class, a control chart referred to as the Frequency control chart and one referred to as the Rate control chart (figure not shown). The Frequency control chart plots the deficiency frequency along with the number of assessments within a specified quarter whereas the Rate control chart plots the number of deficiencies per assessment within a specified quarter.

Along with the frequency of deficiencies or deficiencies per assessment, these control charts consist of three key elements over a three year period by quarter:

1) Centerline: the average number of deficiencies or average deficiencies per assessment over the three years (mean)

2) Upper warning limit (UWL): two times the standard deviation above the mean

3) Upper Control-limit (UCL): three times the standard deviation above the mean

In this analysis, the primary concern was the number of deficiencies above the two upper limits, the UWL and UCL. Therefore the following two other key elements, which are typically part of a control chart are not shown in the charts in this analysis:

4) Lower warning limit ( $L W L$ ): two times the standard deviation below the mean

5) Lower control-limit ( $L C L)$ : three times the standard deviation below the mean

Also the number of deficiencies in a quarter could not be below one or zero, and in many cases the LWL and LCL would have been below one or zero had it been incorporated in the control charts.

The UCL is a common calculation for control charts. In an ideal world, the majority of one's data would lie within the UCL, as defined above and a lower control limit (three times the standard deviation below the mean). Standard deviation is a way to measure how far the observations are from their mean. It is also referred to as a measure of spread. 
With these charts, we are looking for special causes of variation. This type of variation can be found by using common tests:

1) One data point falling above the UCL or below the LCL

2) Two consecutive points above the UWL or UCL or below the LWL or LCL

3) One data point above the UWL

4) Single increase in data points for the quarter in question,

5) Increasing trend for more than one quarter

6) Sustained increase or decrease in the number of data points above or below one standard deviation

A point above the UCL or two consecutive points above the UWL (the first two tests of variation) is considered an action limit. Theoretically, if a process is 'in-control' then none of the data points will fall outside of the UCL. If the action limit is met for a compliance code title, the deficiencies are analyzed in the third step to determine if this compliance code title should be reported to NTS. If the compliance code title meets one of the test criteria above, but has already been reported to NTS, further explanation will not be provided.

The four final tests of variation are not considered action limits. These are used to identify compliance code titles that may be of interest and will be watched during the quarter and the analysis reported in the next quarterly report. The purpose of the watch list is to watch certain compliance code titles in future quarterly reports for consecutive increases in deficiencies and an escalation in point(s) above one of the control limits. Those deficiencies with compliance code titles that make the watch list in this quarterly analysis will automatically be analyzed next quarter using control charts.

During this period, internal assessments were primarily performed by directorates and by the ES\&H Assurance Office. Assessments on specific compliance areas were required to be conducted at least triennially and were scheduled independently. Therefore, the variation in number of assessments conducted in any one quarter and entered in ITS may be substantial and may significantly affect the number of deficiencies identified. If a data point falls above the UWL or UCL on the Frequency control chart, but below the UWL or UCL on the Rate control chart, this suggests that the point outside of one of the limits may have been due to an increase in the number of assessments that quarter. This information is considered in the analysis and may indicate a need to obtain additional information on the related assessments.

\section{Worker Safety and Health Results}

Based on the frequency of deficiencies by the compliance code titles among the last 13 quarters, six compliance code titles, compared to last quarter, revealed the need for control charts:

- emergency egress,

- fall protection,

- fire alarms,

- fire prevention, 
- general hygiene,

- laser

The following six compliance code titles, and one compliance code heading (explosive safety) were placed on the watch list last quarter and require continued analysis this quarter:

- chemical storage,

- crane/hoist,

- electrical,

- explosive safety

- ladders/scaffolding,

- ventilation systems,

- walking working surfaces

As discussed in the sections, below, the analysis for worker safety and health deficiencies identified two subject areas (General Hygiene, and Lasers) with increased deficiencies in the January - March 2008 quarter.

\section{Emergency Egress}

During the January - March 2008 quarter there was a slight decrease in the number of emergency egress deficiencies, from 37 in the fourth quarter of 2007 to 33 in the January March 2008 quarter, as shown in Frequency chart 1.Twenty one $(64 \%)$ of the emergency egress deficiencies were categorized as, Illumination of means of exit or directional signs are not adequate. Ten of the 21 were from the same assessment, the 2006 Exterior Lighting Assessment. Emergency egress deficiencies also had a point above the UWL in the third quarter of 2005, as shown on the Frequency chart 1.

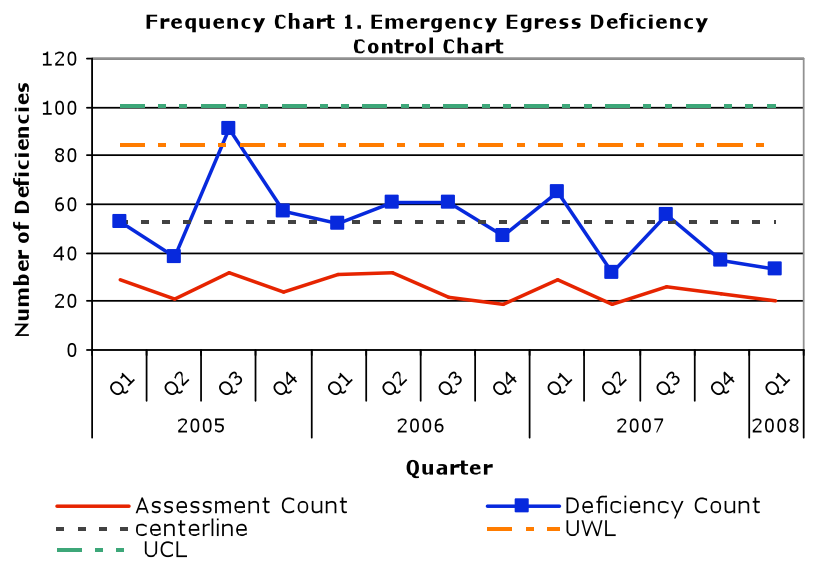
However, this same point was proven to be escalated by the number of assessments performed during that particular quarter, since it was below the UWL on the corresponding Rate chart (figure not shown). Since the point above the UWL was prior to 2007, this compliance code title will not be placed on the watch list for the next quarterly report. 


\section{Fall Protection}

During the January - March 2008 quarter the number of fall protection deficiencies decreased from 14 in the fourth quarter of 2007 to six in the January - March 2008 quarter, as shown in Frequency chart 2. Five of the six fall protection deficiencies were from the same assessment, B131FAC-MSA-FEB08-1 st $^{\text {st }}$ Floor N/E. All six were categorized under fall protection as, not otherwise specified deficiencies.

However based on the deficiency title, five of the six were titled as, " $1^{\text {st }}$ Floor N/E Strap Top Shelves". The other deficiency was titled as, "a worker not tied off on platform on top of target chamber". In general, fall protection deficiencies increased from the first to the third quarter in 2007 from zero deficiencies in the first quarter, two in the second quarter and 15 in the third quarter. However the number of assessments also increased from zero in the first quarter, two in the second quarter and 10 in the third quarter. All 15 deficiencies in the third quarter of 2007 were from 10 different NIF Safety walks. On the Rate chart (figure not shown) there were four consecutive increases in the number of deficiencies per assessment. Although the increases are small, from one in the second quarter of 2007 to three in the first quarter of 2008, this compliance code title will be placed on the watch list.

\section{$\square$ Reportable to NTS}

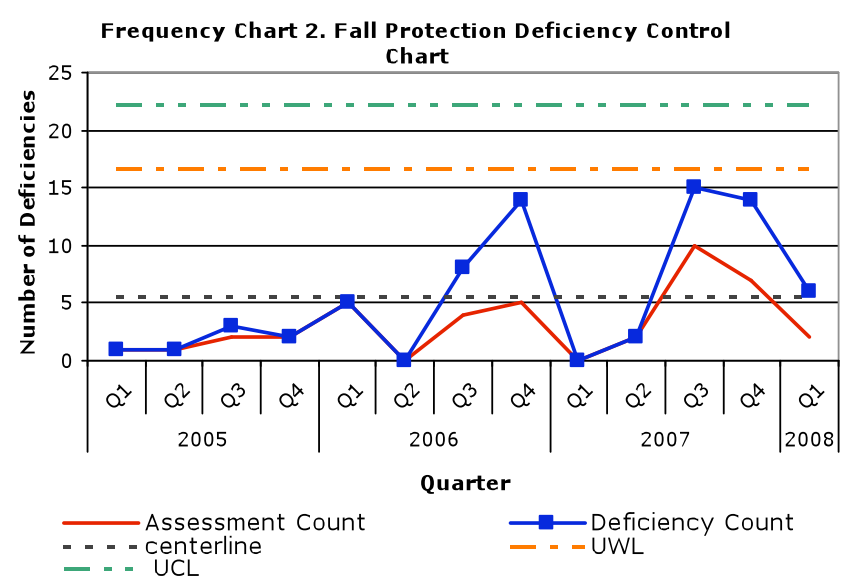

- - - - centerline $\square$ Not reportable to NTS

$\bigotimes$ Watch List

\section{Fire Alarms}

During the January - March 2008 quarter the number of fire alarm deficiencies decreased from nine in the fourth quarter of 2007, to one in the January - March 2008 quarter, as shown in Frequency chart 3. This deficiency was titled as, "Manual pull station Z10-4 requires relocation or removal". None of the 2007 or 2008 data points on Frequency chart 3, for compliance code title fire alarms, met the common tests described in the methods section. Therefore this compliance code title is not discussed further and will not be placed on the watch list.

\section{Reportable to NTS}

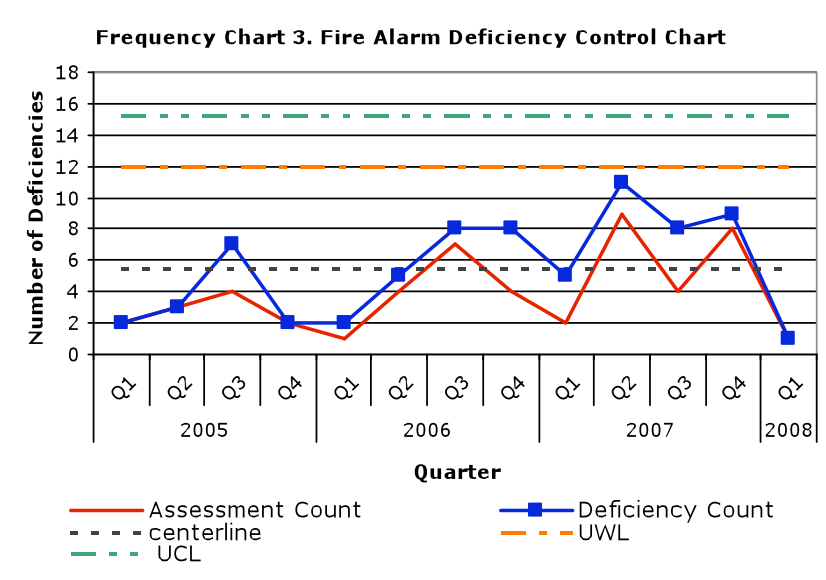

$\triangle$ Not reportable to NTS 


\section{Fire Prevention}

During the January - March 2008 quarter the number of fire prevention deficiencies decreased from 58 in the fourth quarter of 2007 to 21 one in the January - March 2008 quarter, as shown in Frequency chart 4 . Ten $(48 \%)$ of the twenty one deficiencies were categorized as, Integrity of fire barrier and/or smoke barrier is compromised (due to holes in rated walls, missing ceiling tiles, blocked/wedged fire doors, etc.). These ten deficiencies were spread across five different assessments, although all five were an FPO walkthrough, just done at different times, in different facilities. None of the 2007 or 2008 data points on Frequency chart 4, for compliance code title fire prevention, met the common tests described in the methods section. Therefore this compliance code title is not discussed further and will not be placed on the watch list.

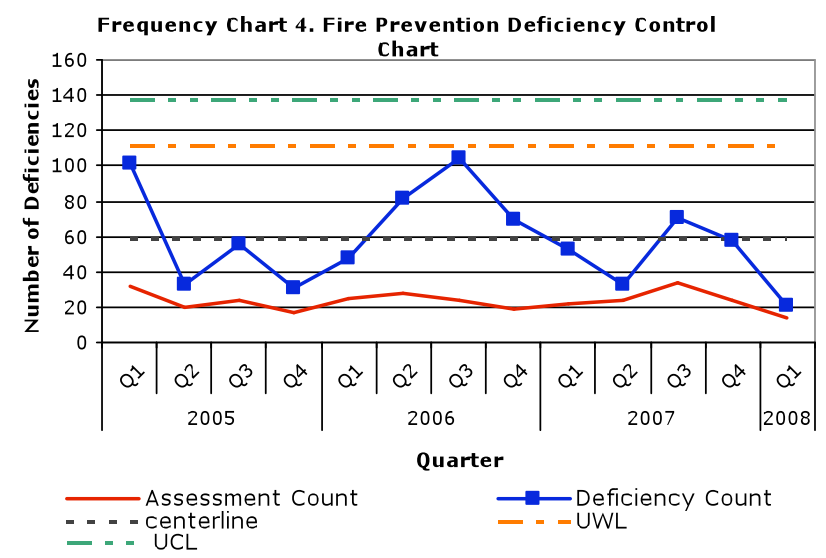

Reportable to NTS

$\bigotimes$ Not reportable to NTS

Watch List

\section{General Hygiene}

During the January - March 2008 quarter the number of general hygiene deficiencies increased from 23 in the fourth quarter of 2007 to 48 in the January - March 2008 quarter, as shown in Frequency chart 5. Twenty one (44\%) were categorized as, not otherwise specified deficiencies. Fourteen (29\%) were categorized as, Unsanitary conditions exist in refrigerator, microwave oven, food preparation area, food storage area, utensils, floors, etc. These 14 deficiencies were from five different assessments. Since this compliance code title had an increase in the number of deficiencies for the first quarter in 2008 , it will be placed on the watch list.

General Hygiene deficiencies also increased from the first to the third quarter in 2007, shown in Frequency chart 5. However the same trend was not present on the Rate chart (figure not shown), implying that the increasing trend over the two quarters was due to an increase in the number of assessments. Specifically, the number of deficiencies per assessment was 1.81 in the first quarter of 2007, 1.78 in the second quarter of 2007 and 2.20 in the third quarter of 2007.

\section{Reportable to NTS}


Laser

During the January - March 2008 quarter the number of laser deficiencies increased from nine in the fourth quarter of 2007 to 16 in the January - March 2008 quarter, as shown in Frequency chart 6 . These 16 deficiencies were from seven different assessments with six of the deficiencies categorized as, Laser specific warning signs are not accurate, are missing, and/or are not conspicuously displayed where they will best serve to warn onlookers. Note that in the fourth quarter of 2007, the nine deficiencies were from only four assessments. The rate of deficiencies per assessment was basically the same in the fourth quarter of 2007 (2.25) and the January - March 2008 quarter (2.29), implying that the increase in the number of deficiencies was due to the increase in assessments. However, since the number of laser deficiencies increased in the January - March 2008 quarter, this compliance code title will be placed on the watch list.

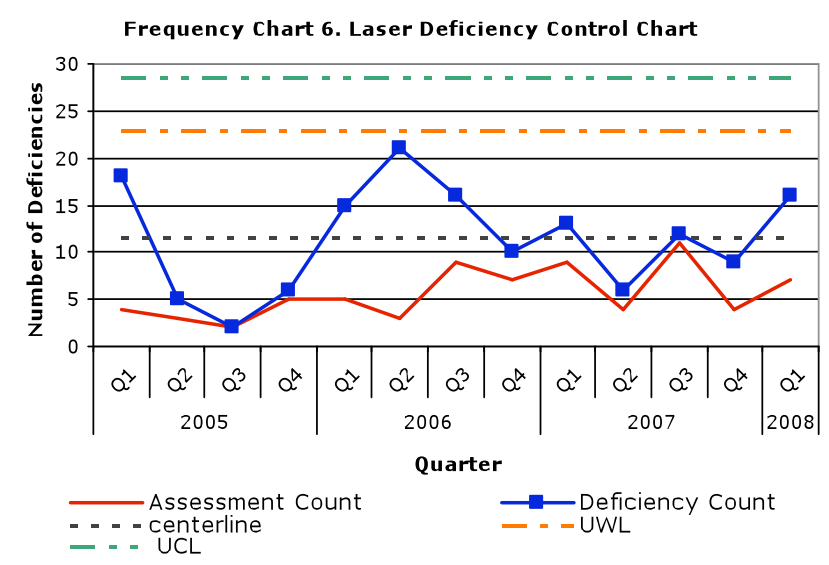

Reportable to NTS Not reportable to NTS

$\bigotimes$ Watch List

\section{Chemical Storage}

During the January - March 2008 quarter the number of chemical storage deficiencies decreased from 14 in the fourth quarter of 2007 to 13 in the January - March 2008 quarter, as shown in Frequency chart 7. These 13 deficiencies were from eight different assessments, with eight categorized as, not otherwise specified deficiencies. Chemical storage deficiencies were previously put on the watch list in last quarters report, since the number of deficiencies increased from the first to the third quarter in 2007, as shown in Frequency chart 7. However, the number of assessments is also increasing. For the second

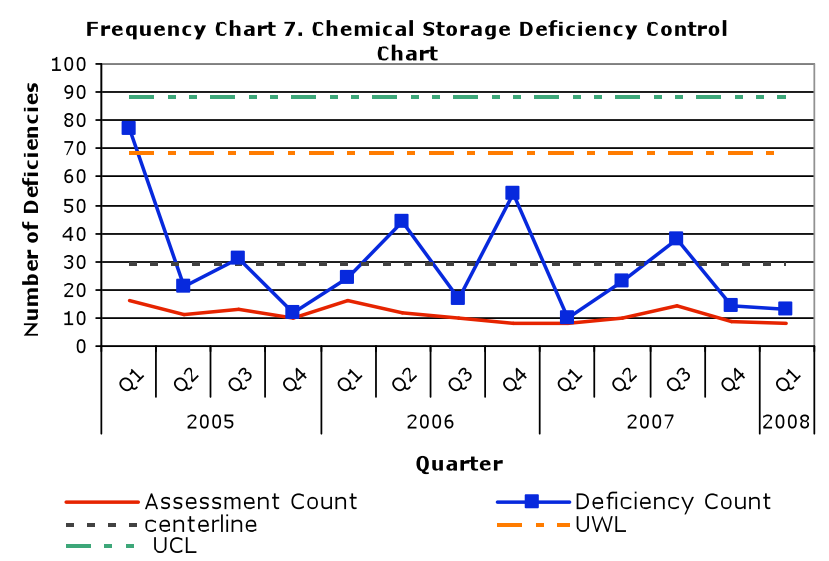
quarter in 2007, there were 10 assessments performed with 23 deficiencies found ( 2.3 deficiencies per assessment). In the third quarter of 2007, there were 14 assessments with 38 deficiencies found (2.71 deficiencies per assessment). For the quarter in question, the first in 2008, the number of deficiencies and assessments decreased by one. This compliance code title will be removed from the watch list, since the data does not suggest a programmatic issue and no new common tests were met. 


\section{Crane/Hoist}

During the January - March 2008 quarter the number of crane/hoist deficiencies decreased from seven in the fourth quarter of 2007 to one in the January - March 2008 quarter, as shown in Frequency chart 8 . This deficiency was titled, "Two rigging shackles with no current inspection," and found during the NIF Safety Walks. Crane/hoist deficiencies were previously put on the watch list due to a data point above the UWL in the first quarter of 2007, as shown in Frequency chart 8.

More specifically, there were 39 crane/ hoist deficiencies in the first quarter of 2007, from five different assessments with approximately eight deficiencies per assessment that quarter. Of

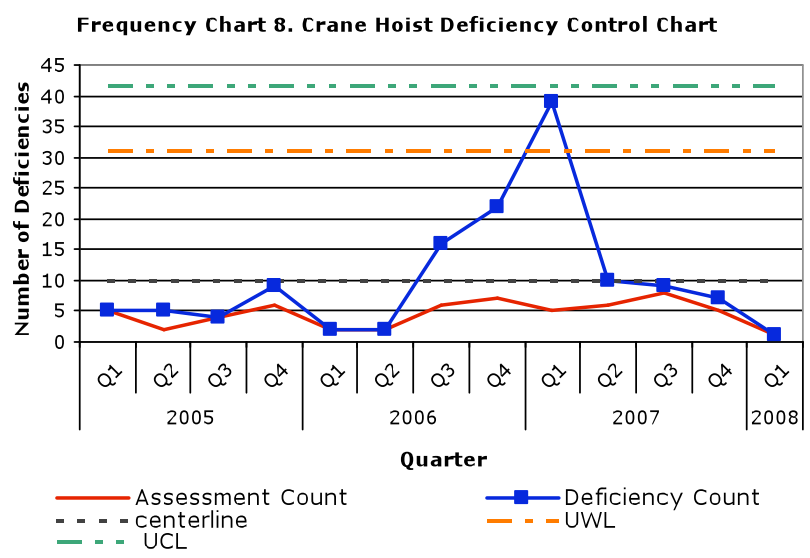
these 39 deficiencies, 10 had a facility assigned, with five different facilities identified. Thirty seven of the 39 deficiencies were categorized as, not otherwise specified deficiencies, with one categorized as, Required labels on crane and/or hoist are missing, illegible, or inadequate and Rigging equipment is damaged, unapproved, and/or has not been maintained as required. In analyzing the deficiencies categorized as not otherwise specified, 27 of the 37 are not true deficiencies, but are more informative; with a deficiency description of, Please invite John or Steve to attend your next monthly safety meeting to review the requirements of Chapter 18 of the P2 manual with all of your work center employees. Without these 27 deficiencies the number of deficiencies per assessment for the first quarter in 2007 would be 2.4 , bringing the point that was above the UWL, below the UWL. Therefore this compliance code title will be removed from the watch list.

Reportable to NTS

$\triangle$ Not reportable to NTS Watch List

\section{Electrical}

During the January - March 2008 quarter the number of deficiencies decreased by one with 210 in the fourth quarter of 2007 to 2009 in the January - March 2008 quarter, as shown in Frequency chart 9 . Fifty six percent $(56 \%)$ were from the assessment titled, "Disposition of Baseline AHJ Inspection of Engineering Equipment." All of these deficiencies (116) were categorized as, Equipment (e.g., small appliances, multi-outlet strip or box) is not listed by UL or other recognized testing lab.. Electrical deficiencies were put on the watch list due to an increase in deficiencies from the second to the fourth quarter in 2007, as shown in Frequency chart 9.

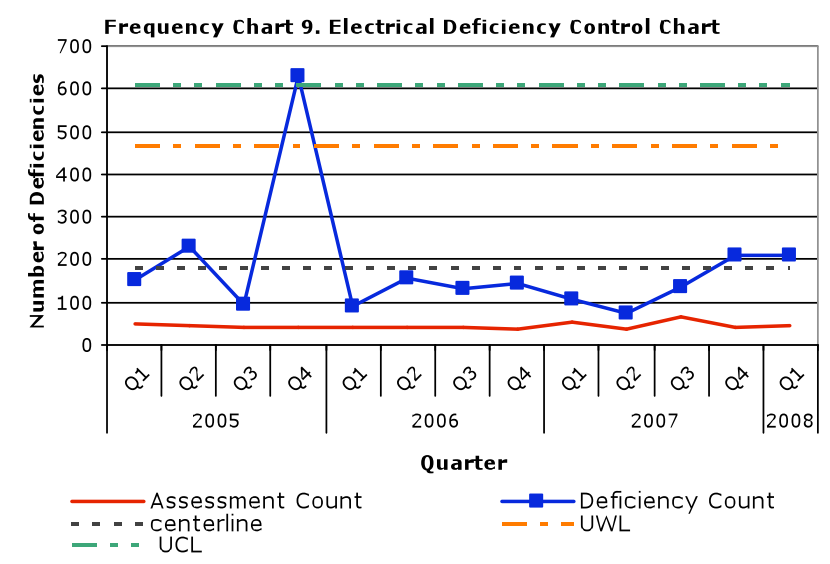
- - - centerline - - Deficier 
However, in the first quarter of 2008, the number of assessments increased by two and the number of deficiencies decreased by one. Although this compliance code title should be removed from the watch list, since none of the common tests were met this quarter, due to the type of deficiencies it will remain on the watch list for future quarters.

\section{Explosive Safety}

During the January - March 2008 quarter there were no assessments performed where explosive safety deficiencies were found, as shown in Frequency chart 10. This compliance code title was previously put on the watch list due to an increase in deficiencies from the second to the fourth quarter in 2007. However, there were no deficiencies recorded in ITS for the first quarter in 2008, so the number of deficiencies has not continued to increase. This compliance code title will remain on the watch list for the next quarterly report because it may be that these assessments and deficiencies were

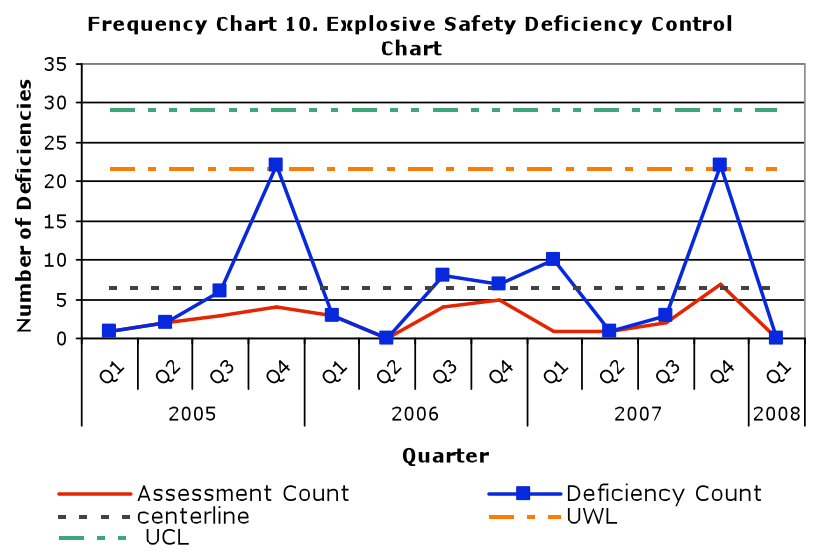
not in ITS at the time the data was extracted.

Explosive safety deficiencies also had a point above the UWL in the fourth quarter of 2005 and the fourth quarter of 2007. The point above the UWL in the fourth quarter of 2007 were below the UWL on the Rate chart (figure not shown), suggesting that the increase in the number of deficiencies was due to an increase in the number of assessments. The point above the UWL in the fourth quarter of 2005 was not below the UWL on the Rate chart (figure not shown). However, since this point was prior to 2007, it will not be discussed further.

\section{Ladders/Scaffolding}

During the January - March 2008 quarter the number of ladder/scaffolding deficiencies decreased from 20 in the fourth quarter of 2007 to five in the January - March 2008 quarter, as shown in Frequency chart 11. These five deficiencies were from four different assessments, two related to stools, one related to metal ladders, one related to wooden ladders and one related to the tagging of a ladder.

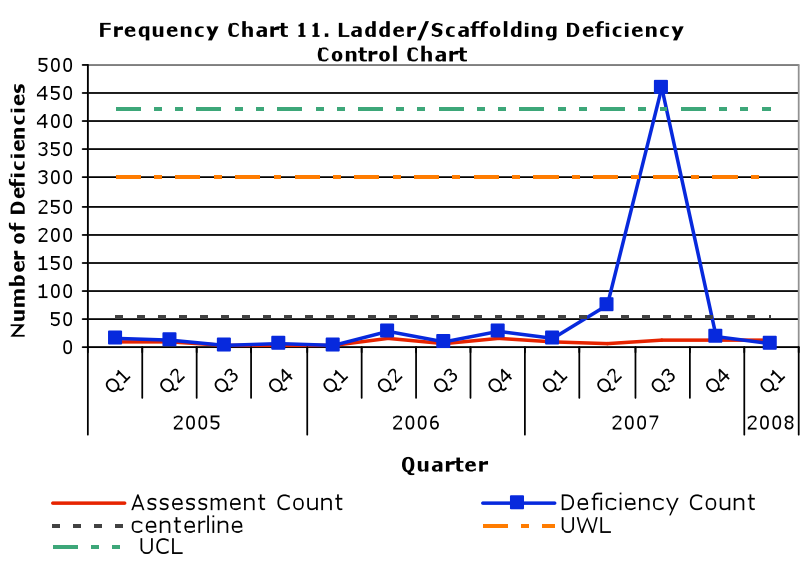


As discussed in the last quarterly report, ladder/scaffolding safety had a significant increase in the number of deficiencies in the third quarter of 2007, as shown in Frequency chart 11. This significant increase is due to the findings from a comprehensive assessment on fixed ladders, an action from the ladder event in 2006. In the fourth quarter of 2006 a noncompliance report was submitted to the NTS for the ladder event titled, "Employee fall from ladder at trailer 6179 results in multiple fractures." Due to the ladder event in 2006, ladder/scaffolding safety will remain on the watch list for future quarters.
Reportable to NTS
$\square$ Not reportable to NTS
$\bigotimes$ Watch List

\section{Ventilation Systems}

During the January - March 2008 quarter the number of ventilation system deficiencies decreased from 11 in the fourth quarter of 2007 to two in the January - March 2008 quarter, as shown in Frequency chart 12.

Ventilation system deficiencies were previously put on the watch list since there was an increase in deficiencies for the fourth quarter in 2007 and a point above the UWL in the second quarter of 2007, as shown in Frequency chart 12. Sixteen of these 28 deficiencies (57\%) that raised the point above the UWL were categorized as, ventilation control systems are not present where required, are inadequate or are not being used according to requirements. As discussed in last quarter's analysis, the point above the UWL in the second quarter of 2007 on the Frequency chart was below the UWL on the Rate chart (figure not shown), suggesting that the increase in deficiencies is due to an increase in assessments that quarter. Since there was a decrease in deficiencies for the quarter in question, the first quarter in 2008 , ventilation systems will be removed from the watch list.

\section{Reportable to NTS $\quad$ Not reportable to NTS}

$\square$ Watch List

Walking Working Surfaces

During the January - March 2008 quarter the number of walking working surface deficiencies decreased from 22 in the fourth quarter of 2007 to 12 in the January - March 2008 quarter, as shown in Frequency chart 13. These 12 deficiencies were from 11 different assessments with nine of the 12 categorized as, Walking working surface is not clear of obstructions and trip hazards. Walking working surface deficiencies were previously put on the watch list since there

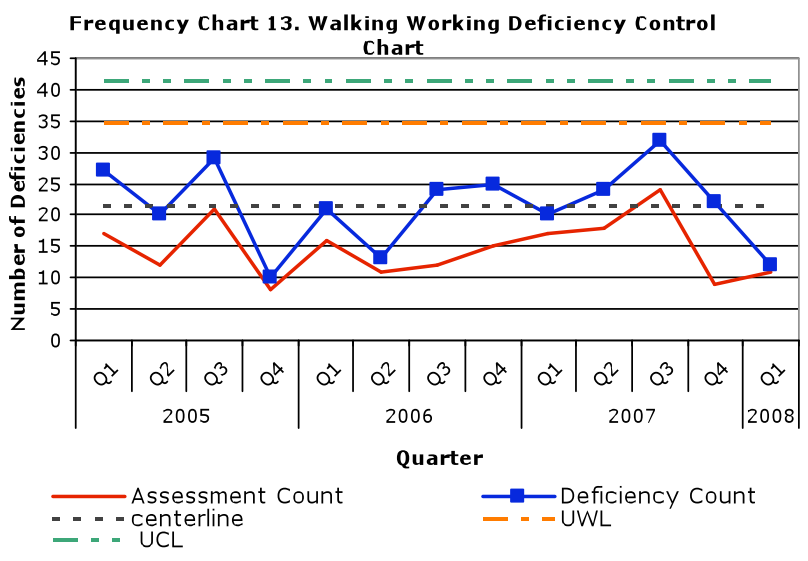


was an increase in deficiencies from the first to the third quarter in 2007. However, since the third quarter in 2007, the number of deficiencies has decreased from 32 in the third quarter of 2007, 22 in the fourth quarter of 2007 and 12 in the first quarter of 2008. Therefore this compliance code title will be removed from the watch list.

Reportable to NTS

$\bigotimes$ Not reportable to NTS

$\square$ Watch List

\section{Nuclear Safety Results}

Nuclear safety assessments consists of deficiencies categorized as radiation protection, safety basis and criticality safety. Safety basis deficiencies are not discussed in the following section because there were only two deficiencies categorized as safety basis deficiencies since January 2008, when safety basis compliance codes were added to ITS.

Based on the frequency of deficiencies by the compliance code titles within the "safety and health" class, among the last 13 quarters, five nuclear safety related compliance code titles and one related compliance code heading (criticality safety) revealed the need for control charts:

- criticality safety,

- radiation protection program,

- radiation safety and training,

- radiation safety-posting/labeling,

- radiation safety records,

- sealed radioactive source control

This report is the first time that the nuclear safety deficiencies have been included in this analysis. Therefore, this section discusses these nuclear safety deficiencies identified over the period shown on the control chart in addition to the deficiencies entered during the January March 2008 quarter. Note that data for the third and fourth quarters in 2007 include deficiencies identified during the LLNS due-diligence walkdown inspections of LLNL facilities prior to and immediately after the contract transition period, as discussed in section 3.0 of this report.

As discussed in the sections below, the analysis for nuclear safety identified two subject areas (Radiation Protection Program, and Radiation Safety and Training) with increased deficiencies in the January - March 2008 quarter.

\section{Criticality Safety}

During the January - March 2008 quarter there were no assessments performed where criticality safety deficiencies were found, as shown in Frequency chart 14. There was one point that came close to the UWL in the first quarter of 2007. This is due to six of the 25 criticality safety deficiencies entered into ITS since 2005, falling in the same quarter. These six deficiencies were from six different assessments. 
Overall there are few deficiencies categorized as criticality safety, as mentioned above, 25 recorded in ITS since 2005, as shown in Frequency chart 14. Fifteen of the 25 deficiencies were categorized as posting and labeling deficiencies, six as safety limit deficiencies, and four as alarm system deficiencies.

Four of the 15 categorized as posting and labeling deficiencies were from two assessments in the fourth quarter in 2007 titled, “2007 B362 Q4 FPOC Walkthrough" (one deficiency) and the "AO-Triennial Suspect/Counterfeit Items 2007" (three deficiencies). After a more detailed review of the 15 deficiencies categorized as criticality safety-posting/labeling, it was determined that only two were categorized correctly, with the remaining 13 deficiencies not related to criticality safety. For example, a couple of deficiencies

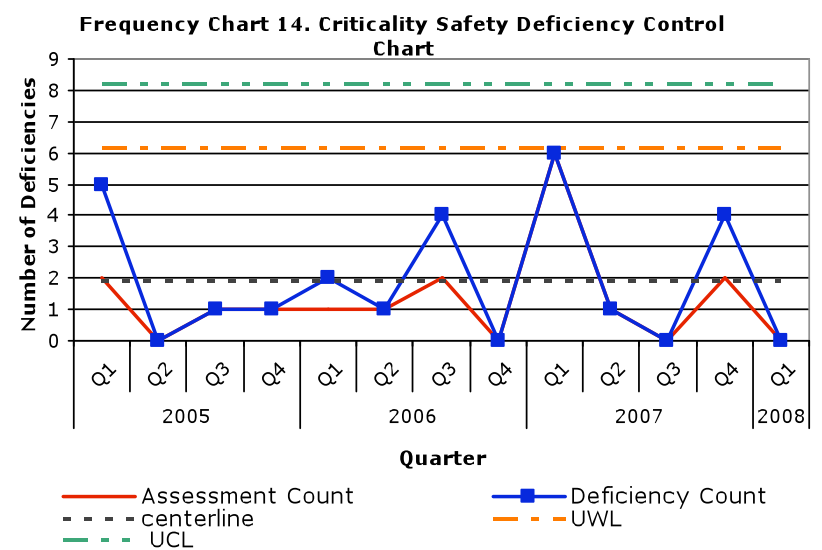
categorized under criticality safety incorrectly had the following deficiency descriptions in ITS, cream cheese sitting out for too long, the toaster oven is located on top of a microwave and needs to be seismically secured, the check hands and shoes sign is not posted on inside of lab and exit sign in not visible from the hallway. All six of the safety limit deficiencies were categorized correctly as criticality safety deficiencies. However none of the four alarm system deficiencies were categorized correctly as criticality safety.

Therefore, because the majority of the data was not accurately categorized as criticality safety, this compliance code title is not discussed further, not placed on the watch list and Frequency chart 14 should not be used as an analysis tool.

Reportable to NTS $\quad \square$ Not reportable to NTS

Watch List

Radiation Protection Program

During the January - March 2008 quarter there was an increase in radiation protection deficiencies from five in the fourth quarter of 2007 to 12 in the January - March 2008 quarter, as shown in Frequency chart 15. The 12 deficiencies were from seven assessments, three of which were 10CFR835 Triennial RPP Reviews performed in different facilities. Of these 12 deficiencies, two were inadequate contamination surveys in fume hoods used for handling radioactive materials. The text of these two deficiencies states that "this condition was found to exist in a few other areas of the institution."

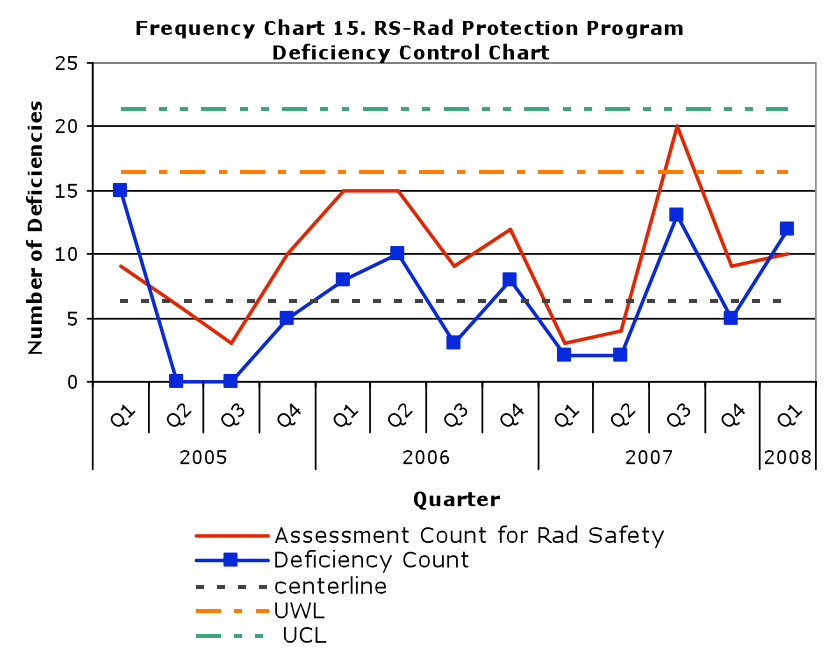


When these deficiencies were first identified, the Hazards Control Department, Radiation Safety Section (RSS), asked health physicists during a weekly health physics technical meeting what they were doing regarding contamination surveys inside hoods. This query found a couple of HPs who were under the impression that monitoring inside hoods was not expected. The query further found that most of the HPs in fact routinely prescribed and/or expected surveys from within the hood. Based on these results, RSS determined that a "site-wide issue" did not exist. Nevertheless, in order to clarify the expectation, RSS developed a new HP-DAP Instruction (HP-83) and included it in the Master HP-DAP. All HP-DAPs have since been updated accordingly.

For the 12-month period, April 2007 - March 2008 there were 32 deficiencies entered into ITS. These are summarized in Table 3.

Table 3. Frequency and Description of Radiation Protection Deficiencies from April 2007 - March 2008

\begin{tabular}{|cl|}
\hline Frequency & Deficiency Description \\
\hline 12 & Inadequacies in DAPs and TAPS \\
\hline 6 & Implementation of specific RGD program requirements \\
\hline 4 & General document and record deficiencies \\
\hline 2 & N/A-Reported in the NTS \\
\hline 2 & Contamination surveys not being done \\
\hline 2 & Compliance with procedures \\
\hline 2 & Inventory record keeping inadequacies \\
\hline 1 & Implementation of programmatic aspects of the RGD program \\
\hline 1 & Hazard characterization deficiencies \\
\hline
\end{tabular}

Our analysis concludes that there are systemic issues related to the RGD program and inadequacies in the DAPs and TAPs. Both of these issues have been reported NTS 2008-0001 and are being addressed in corrective actions for findings report regarding "insufficient resources to manage risks associated with the conduct of current radiological operations" and the lack of a "formal, standardized document development and control system to ensure consistent technical and programmatic review of Radiation Safety Program procedures." .

Note: The results of an independent internal assessment of the institutional radiation protection program performed during the third quarter of 2007 were reported to the NTS on January 4, 2008, report number LLNL-2008-0001. However, since a common test was met, this compliance code title will be placed on the watch list.
$\square$ Reportable to NTS
Not reportable to NTS
Watch List 


\section{Radiation Safety Training}

During the January - March 2008 quarter there was an increase in radiation safety and training deficiencies from one in the fourth quarter of 2007 to six in the January - March 2008 quarter, as shown in Frequency chart 16. Since January 2005, only 19 deficiencies have been categorized as radiation safety and training.

During the 12-month period of April 2007 March 2008 there were eight deficiencies related to radiation safety training. Five of the eight were failure to complete Facility Safety Plan (FSP) training, three of which involved a total of 5 employees who had not completed training for the same FSP out of the 281 who were required to take it. The remaining three deficiencies involved 30 individuals who failed to complete IWS-required training out of more than 550 who were required to take it. Therefore these are not considered systemic or programmatic noncompliances.

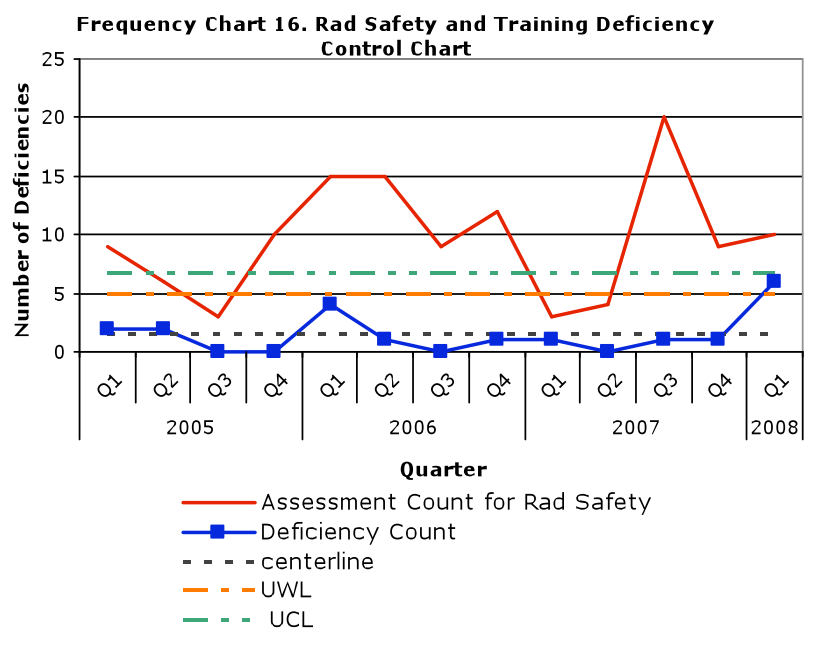

Six of the eight deficiencies had notification dates in the first quarter of 2008, causing a point to be above the UWL, close to the UCL. These six deficiencies were from the 10CFR835 Triennial RPP Review. All six were categorized as, Individuals have not completed radiation safety training required for their workplaces or work activities. Since a common test was met, this compliance code title will be placed on the watch list.

Reportable to NTS

Radiation Safety-Posting/Labeling

During the January - March 2008 quarter there was a decrease in radiation safetyposting/labeling deficiencies from six in the fourth quarter of 2007 to four in the JanuaryMarch 2008 quarter, as shown in Frequency chart 17. These four deficiencies were from four different assessments, with two categorized as, Access points to controlled areas or various radiological areas are not appropriately posted (e.g., do not contain the approved trefoil symbol, do not match the radiological area, etc.). The other two were categorized as, Radiological labeling is not adequate for those individual items and containers required to be labeled. None of the 2007 or 2008 data points on Frequency chart 17, for compliance code title radiation safety-posting/labeling,

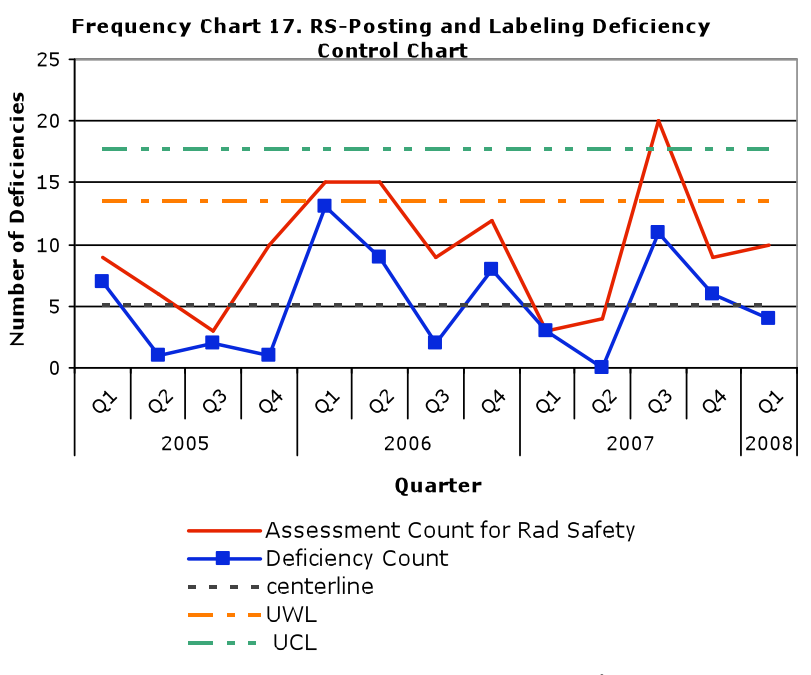


met the common tests described in the methods section. Therefore this compliance code title is not discussed further and will not be placed on the watch list.
Reportable to NTS
$\bigotimes$ Not reportable to NTS
Watch List

\section{Radiation Safety Records}

During the January - March 2008 quarter there were no assessments performed where radiation safety record deficiencies were found, as shown in Frequency chart 18. The number of deficiencies reported in the third quarter of 2007 created a point almost at the UWL, as shown in Frequency chart 18 . Nine of the 11 deficiencies came from the 10CFR835 Internal Audit of ES\&H Teams 2 and 3. Ten of the 11 deficiencies were categorized as, Radiological records are not adequately maintained to document compliance with 10 CFR 835, Subpart H. Frequency chart 18 displays the number of assessments for all radiation safety compliance code titles. Since this is the first time the nuclear safety noncompliances have been analyzed and there was a point almost at the UWL, this compliance

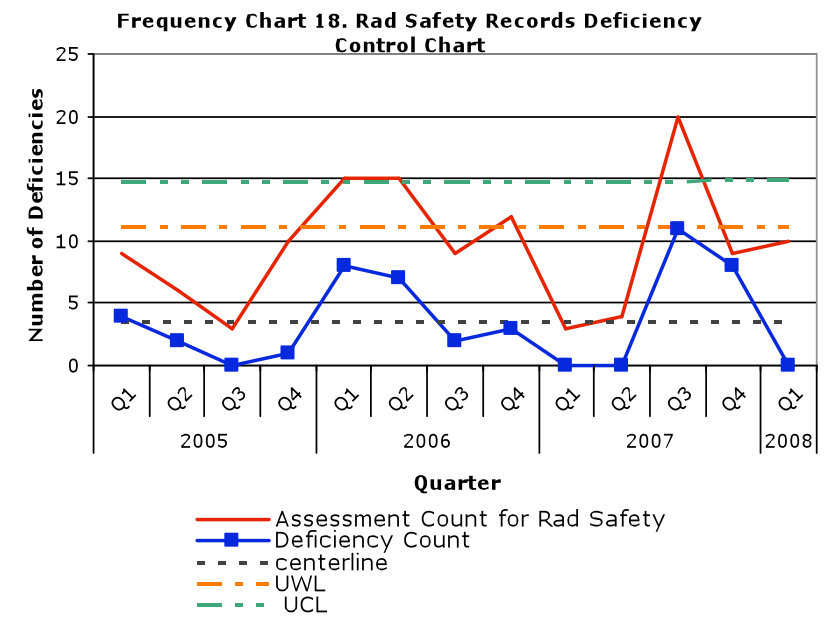
code title will be placed on the watch list.

\section{Reportable to NTS}

Sealed Radioactive Source Control

During the January - March 2008 quarter there were no assessments performed where sealed radioactive source control deficiencies were found, as shown in Frequency chart 19. There are very few sealed radioactive source control deficiencies in ITS, with 13 reported into ITS since January 2005.

Five deficiencies were reported in 2007; and three of these were associated with a single occurrence. These three are categorized as, Accountable sealed sources were not appropriately inventoried, leak tested, or controlled (two were related to

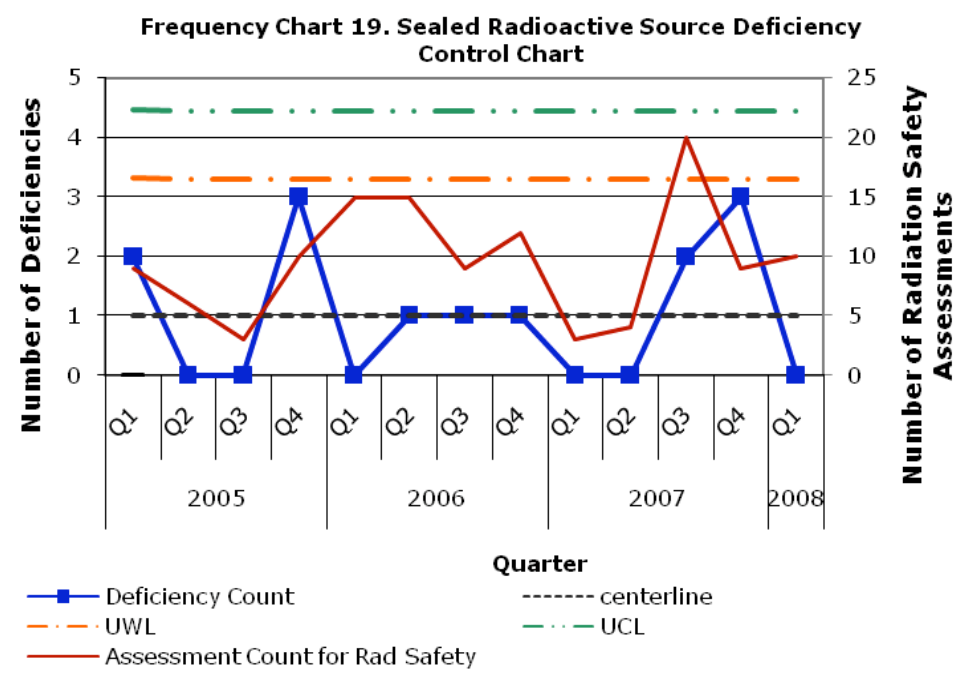
labeling and one was a failure to enter the source into the institutional sealed source inventory). Two of the five were from two 
different assessments: the LLNS Due Diligence Walkdown (inadequate work permit) and one of the 10 CFR 835 Audit of the Radiation Safety Program (missed leak test). Based on this analysis these deficiencies comprise a set of unrelated deficiencies that do not collectively constitute a programmatic or systemic noncompliance for sealed source management.

However, since sealed radioactive source control deficiencies had a recent increasing trend over two quarters, as shown in Frequency chart 19, this compliance code title will be placed on the watch list.

$\square$ Reportable to NTS 


\section{3 "Other Significant Condition" Noncompliances}

The WSH 'Other Significant Condition' NTS reporting threshold would include, at a minimum, significant noncompliances with high relative risk, as defined in ESEH Manual Document 4.4.

\section{Method}

These deficiencies are identified in ITS as having a Priority 1A. There were two methods used to review ITS data for deficiencies that may meet the 'Other Significant Condition' NTS reporting threshold:

1. A review of all Priority $1 \mathrm{~A}$ and $1 \mathrm{~B}$ deficiencies with notification dates starting in January through March 2008.

2. Review of all deficiencies with compliance codes that default to a Priority $1 \mathrm{~A}$, but were downgraded, to confirm that the downgrade was supported.

The ITS data was extracted on March 25, 2008 to review those ITS entries that were prioritized as 1 As, by definition, a non-compliant condition, practice, means, method, operation, or process that presents the highest level of concern and/or liability to the institution, employees, public and/or environment. If found this conditions cannot be abandoned and shall be mitigated or completely corrected before being left unattended.

\section{Results}

There was one deficiency prioritized as a 1A, which was an ORPS-reportable occurrence that resulted in a NTS-reportable noncompliance titled, Electrical Shock at Building 151 during Main Electrical Service Equipment Replacement Project [LLNL-2008-0004]. The noncompliance identified was lack of communication and implementation of controls, which caused the electrical shock.

Four deficiencies with notification dates between January and March of 2008 were prioritized as 1B deficiencies. All four were from the same assessment with three described as, exposed electrical wiring, one as an exposed light socket without a bulb. None of these met a WSH NTS reporting threshold.

There were no deficiencies in the first quarter of 2008 downgraded from a default priority $1 \mathrm{~A}$ to another priority. 


\subsection{How LLNL responded to and managed what is found}

As mentioned in section 3.0, LLNL reported approximately 1\% of WSH and nuclear safety noncompliances to the DOE NTS in the January-March 2008 quarter. Four of these noncompliances were self-identified with titles:

1. "Results of Independent Assessment of LLNL Institutional Radiation Safety Program"

2. "Unexpected Beryllium Contamination and Associated Ducting, Building 695"

3. "Positive USQD-Insufficient Thermal Barrier (B332)"

4. The Implementation of the CBDPP is Inadequate-Uncontrolled Be Work Performed"

Note that one report, "Unexpected Beryllium Contamination and Associated Ducting, Building 695," was reported as both a WSH and nuclear safety noncompliance.

One noncompliance reported to the DOE NTS in the January-March 2008 quarter was identified by an event titled, "Electrical Shock at Building 151 During Main Electrical Service Equipment Replacement Project." Therefore 80\% of noncompliance reports submitted to the DOE NTS in the first quarter of 2008 were self-identified.

The average number of days to report these noncompliances to the DOE NTS, from the date a noncompliance was determined to exist was 35 days. The Office of Enforcement considers prompt reporting to be within 20 days after determining a noncompliance exists.

Comparing CY08 to CY07, the average number of days to report a noncompliance for CY08 was 35 days compared to 32 days in CY07. It is taking longer to report non-event related noncompliances into NTS than event related noncompliances. Reports submitted to the DOE NTS since October 2007 took on average 37 days to report non-event related noncompliances and 30 days for event related noncompliances.

Currently most actions related to NTS reported noncompliances can be extended provided a reason for the extension, which is noted in the NTS system. If an action is from an external assessment, the extension must be granted by the assessing organization and the process to request the extension is more formal, typically in the form of a memo from the LLNL Deputy Director to the assessing organization. As of the data pull on April 1, 2008, 94\% of all the actions completed since January 2007 have been completed on-time. 


\subsection{Conclusion}

The control chart analyses did not identify any compliance code titles, not already addressed in previous NTS reports, which should be investigated as programmatic issues at this time.

The analysis did suggest five WSH related compliance code titles and one compliance code heading that should be placed or remain on the watch list. These compliance code titles and headings will be observed over the next couple quarters for consecutive increases in the number of the deficiencies or points above the control limits:

- electrical safety,

- fall protection,

- explosive safety,

- general hygiene,

- ladder/scaffolding safety,

- laser safety,

There were two WSH related compliance code titles out of "statistical control," with a point above the UCL, electrical safety and ladder safety/scaffolding safety. However the point above the UCL for electrical safety was in the fourth quarter of 2005 and two noncompliance reports have been submitted to the NTS regarding the electrical safety program. The first programmatic noncompliance was identified during the 10 CFR 851 gap analysis, identifying the electrical safety program not in compliance with the 10 CFR 851 requirements and the second recently submitted regarding the electrical safety program and PPE. A noncompliance report has already been submitted to the NTS regarding the employee fall from the ladder, which included the fixed ladder assessment findings that caused the point to be above the UCL. Both of these compliance code titles will remain on future watch lists due to the severity of the type of deficiencies (electrical) and the ladder event that was reported in 2006.

There were two WSH related compliance code titles with points above the UWL and close to the UCL in recent quarters, crane/hoist, and ventilation systems. The majority of the crane/hoist deficiencies that caused a point to be close to the UCL, as described in this report, were entered into ITS incorrectly as deficiencies and were not true noncompliant conditions. The point above the UWL, close the UCL for ventilation systems, was below the UWL on the Rate chart (figure not shown), suggesting that the increase in deficiencies is due to an increase in assessments that quarter. Since this compliance code title was put on the watch list from the last quarterly analysis and there were no signs of continued increases, ventilation systems was removed from the watch list.

There was one WSH compliance code heading, explosive safety with a point above the UWL, not close the UCL in a recent quarter. The same point was below the UWL on the Rate chart (figure not shown), suggesting that the increase in deficiencies is due to an increase in assessments that quarter. However, this compliance code heading will remain on the watch list since thee were no explosive safety deficiencies entered into ITS for the first quarter in 2008. It is 
anticipated that there were explosive safety deficiencies for the January-March 2008 quarter, but maybe there were not entered into ITS by the time the data was extracted.

The analysis also suggested four nuclear safety related compliance code titles that should be placed on the watch list:

- radiation protection program,

- radiation safety and training,

- radiation safety records,

- sealed radioactive source control

None of the nuclear safety related compliance code titles were out of "statistical control", with a point above the UCL.There was one nuclear safety related compliance code title, radiation safety and training, with a point above the UWL and close to the UCL in a recent quarter, the first quarter of 2008. This point consisted of only six deficiencies. However only 19 deficiencies related to radiation safety and training have been entered into ITS since 2005. Therefore six of the 19 reported in the same quarter caused a point to be above the UWL, close to the UCL. This compliance code title was placed on the watch list.

In general discrepancies were found in deficiency categorization. Twenty seven out of 39 crane/hoist deficiencies in the first quarter of 2007 were entered into ITS as deficiencies, but based on the deficiency description, were not true deficiencies. Also three out of 13 sealed radioactive source control deficiencies were entered into ITS as deficiencies, but are technically corrective actions from an Occurrence Report. The method of entry for Occurrence Reports has since been revised so that the event is entered as an issue, with all corrective actions listed below.

Some deficiencies were also found to be improperly categorized as criticality safety deficiencies, 17 of the 25 deficiencies entered into ITS since 2005.

There was only one deficiency which met the "Other Significant Condition" NTS reporting threshold. This deficiency was reported to NTS as event related.

There were no deficiencies in the first quarter of 2008 downgraded from a default priority $1 \mathrm{~A}$ to another priority.

In the January-March 2008 quarter, management reported 1\% of noncompliance to the DOE NTS, which is consistent with past quarters. On average LLNL did not meet the Office of Enforcement Expectation of 20 days to report a noncompliance in the January-March 2008 quarter. However we were close with an average of 35 days. LLNL did self-identify the majority of noncompliances reported to the DOE NTS in the January-March 2008 quarter, as expected by the Office of Enforcement. For all NTS reported actions, completed since January 2007, as of April 1,3008, 94\% of actions have been completed on-time.

The next quarterly report will include both worker safety and health and nuclear safety topics that were placed on the watch list in this analysis. 